\title{
Thrombelastography Should Be Included in the Algorithm for the Management of Postpartum Hemorrhage
}

\author{
Csilla Jámbor $^{a} \quad$ Sybille A. Kozek-Langenecker ${ }^{b}$ Thomas Frietsch ${ }^{c} \quad$ Ralf Knels $^{d}$ \\ ${ }^{a}$ Klinik für Anästhesiologie, Klinikum Großhadern, LMU München, Germany \\ ${ }^{b}$ Clinic for Anesthesiology, General Hospital Vienna, Austria \\ c Clinic for Anesthesiology and Critical Care Medicine, University Hospital Marburg, \\ dGerman Red Cross Transfusion Service East, Institute Dresden, Germany
}

With great interest, we gratefully appreciated the evaluation of an algorithm for life-threatening postpartum hemorrhage by Dr. Goodnough and coworkers [1] in Transfusion recently. However, the transfusion protocol presented neither is evidence-based nor specifically goal-directed towards the leading pathomechanisms of postpartum hemorrhage ( $\mathrm{PPH})[2,3]$. Our criticism concerns the lacking evidence for the used cutoff values employed in this transfusion protocol for INR, platelet count, and fibrinogen. Fibrinogen levels might better be maintained at a higher level above $200 \mathrm{mg} / \mathrm{dl}$ [4] as opposed to $100 \mathrm{mg} / \mathrm{dl}$.

Furthermore, we recommend the use of thrombelastography in addition to standard laboratory tests for two reasons: i) There is a higher rate of hyperfibrinolyses in postpartal hemorrhage and only thrombelastography detects this coagulopathy reliably. ii) The delay between blood sampling and test result information is essential for the choice of the right therapy. We do not agree with the authors' statement that availability of 'super-stat' laboratory results (15-30 min) would be superior to thrombelastography [1]. Even though faster than normally obtained, conventional 'super-stat' laboratory tests do not allow reliable diagnosis of frequent causes evolving in $\mathrm{PPH}$ in a dramatic pace - hyperfibrinolysis, dilution and consumption of coagulation potential [2]. The listed conventional laboratory tests analyze plasma coagulation to the point where clotting starts, but they do not cover fibrin polymerization, interaction with platelets, and fibrinolysis. Measurement of D-dimers have a low test specifity for hyperfibrinolysis [5], whereas multi-channel rotational thrombelastometry $\left(\right.$ ROTEM $\left.^{\circledR}\right)$ enables the valid differentiation of hyperfibrinolysis from other influences such as dilution or colloid effects $[6,7]$. In addition, thrombelastometry is highly sensitive to fibrinogen deficiency [8]. Although regular ROTEM ${ }^{\circledR}$ results usually are obtained after only $100 \mathrm{~s}$ (coagulation time CT), $160 \mathrm{~s}$ (clot formation time CFT) and $15 \mathrm{~min}$ (clot firmness after $15 \mathrm{~min}$ [9], diagnosis of late hyperfibrinolysis may need longer with this method (see also fig. 1). An algorithm based on the solely use of routine laboratory results does not consider the therapeutic option of antifibrinolytic drugs.

Finally, we agree with the authors that for the first minutes of a life-threatening hemorrhage a rigid relationship of red blood cells, plasma, and platelets may be a reasonable advice. However, the adherence to this ratio as designed in their transfusion algorithm will result in an insufficient substitution of both coagulation factors and fibrinogen (the clot substance). The correction of a $60 \%$ loss of plasma in a $70 \mathrm{~kg}$ parturient during ongoing bleeding aiming at a $80 \%$ concentration of coagulation factors requires a volume of $40 \% \times 70 \mathrm{~kg}=2,800 \mathrm{ml}$, equaling 8-10 units. Taking into account the higher average body weight and increased plasma volume of parturients, the needed plasma transfusion volume might increase further. Early use of cryoprecipitate and, if available (as it is in Europe), purified fibrinogen concentrate is recommended to improve efficacy and to avoid massive volume overload. Substitution therapy optimally is guided by thrombelastography (alternative but minor are fibrinogen levels). Other options are the early use of refrigerated or lyophilized plasma as well as the limited use of synthetic colloids [10].

\section{KARGER}

Fax +497614520714

Information@Karger.de

www.karger.com
() 2008 S. Karger GmbH, Freiburg

Accessible online at:

www.karger.com/tmh
PD Dr. Thomas Frietsch

Clinic for Anesthesiology and Critical Care Medicine

University Hospital Marburg

Baldinger Straße, 35043 Marburg, Germany

thomas.frietsch@urz.uni-heidelberg.de 


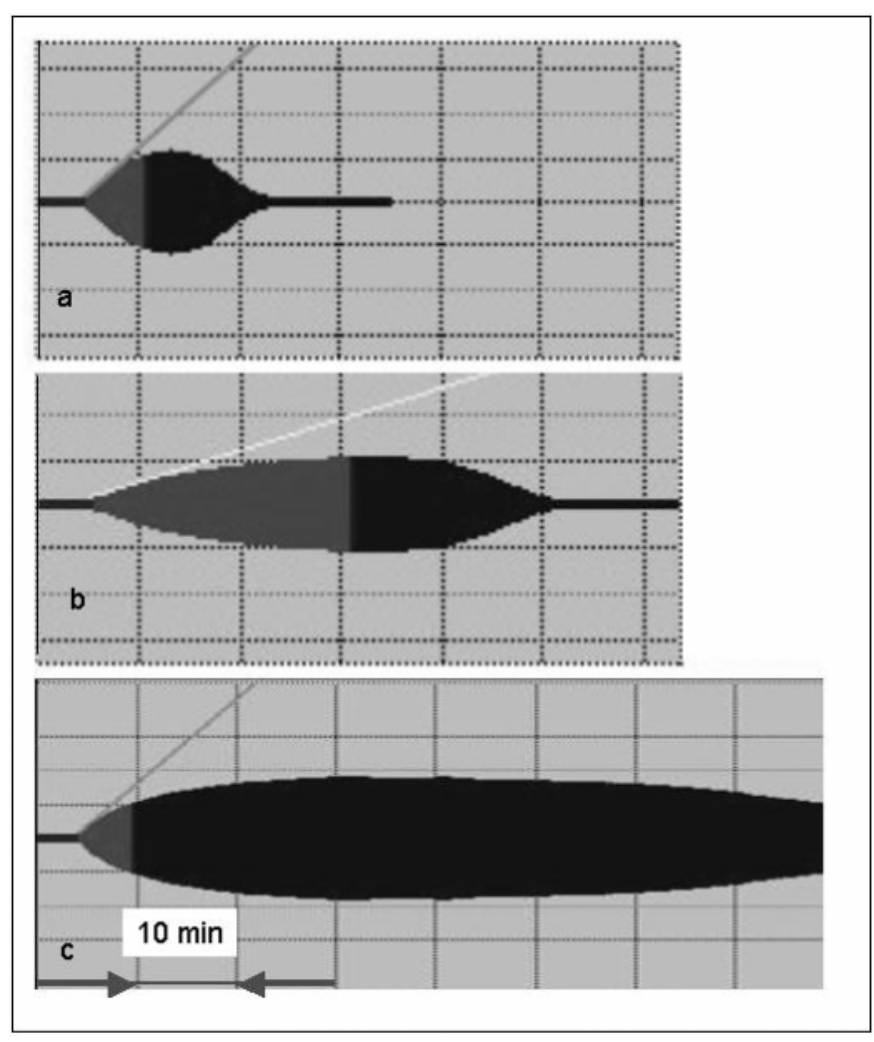

Fig. 1. a Fulminant hyperfibrinolysis shows an immediate breakdown of the clot within $30 \mathrm{~min}$. b Intermediate hyperfibrinolysis with a breakdown of the clot between 30-60 min. c Late hyperfibrinolysis: clot breakdown after $60 \mathrm{~min}$.

\section{References}

1 Burtelow M, Riley E, Druzin M, Fontaine M, Viele M, Goodnough LT: How we treat: Management of life-threatening primary postpartum hemorrhage with a standardized massive transfusion protocol. Transfusion 2007;47:1564-1572.

2 Hellgren M: Hemostasis during normal pregnancy and puerperium. Semin Thromb Hemost 2003;29: 125-130.

3 Whitta RK, Cox DJ, Mallett SV: Thrombelastography reveals two causes of haemorrhage in hellp syndrome. Br J Anaesth 1995;74:464-468.

4 Charbit B, Mandelbrot L, Samain E, Baron G, Haddaoui B, Keita H, Sibony O, Mahieu-Caputo D, Hurtaud-Roux MF, Huisse MG, Denninger MH, de Prost D: The decrease of fibrinogen is an early predictor of the severity of postpartum hemorrhage. J Thromb Haemost 2007;5:266-273.

5 Lang T, von Depka M: Diagnostische Möglichkeiten und Grenzen der Thrombelastometrie/-graphie. Hämostaseologie 2006;26:S20-29.

6 Mittermayr M, Streif W, Haas T, Fries D, Velik-Salchner C, Klingler A, Oswald E, Bach C, Schnapka-Koepf M, Innerhofer P: Hemostatic changes after crystalloid or colloid fluid administration during major orthopedic surgery: The role of fibrinogen administration. Anesth Analg 2007;105: 905-917.

7 Luddington RJ: Thrombelastography/thrombo-elastometry. Clin Lab Haematol 2005;27:81-90.

8 Gottumukkala VN, Sharma SK, Philip J: Assessing platelet and fibrinogen contribution to clot strength using modified thromboelastography in pregnant women. Anesth Analg 1999;89:1453-1455.

$\checkmark 9$ Kozek-Langenecker S: Management of massive operative blood loss. Minerva Anestesiol 2007;73: 401-415.

10 Kozek-Langenecker SA: Effects of hydroxyethyl starch solutions on hemostasis. Anesthesiology 2005;103:654-660. 